\title{
Brentano as a Logicist
}

\author{
Carlo Ierna
}

The Brentanist Philosophy of Mathematics

In the present contribution I would like to make three related claims: 1 ) There was an original and shared philosophy of mathematics in the School of Brentano; 2 ) In the School of Brentano mathematics was considered as the paradigmatic and foundational science, and more specifically as deductive, analytic, and a priori; 3) Brentano founds the concept of number on elementary logical operations, i.e. Brentano was a logicist. I will concentrate mainly on the third claim, using the other two as background and support.

The first thesis is essentially a historical thesis, which can be simply and straightforwardly proven by pointing out the existence and content of certain sources. For instance, we can point out the existence of works written by members of the School of Brentano that have as central topic the philosophy of mathematics. The first of these works would be Carl Stumpf's 1870 Habilitation thesis Über die Grundsätze der Mathematik ("On the Foundations of Mathematics" or "On the Mathematical Axioms"). Therein Stumpf advances several theses that lead directly to our second claim. Specifically, that mathematics would be a priori: "The critique of Mill's theory has shown that the mathematical axioms (as well as its propositions) cannot be founded on induction, but that they must be necessary a priori." (Stumpf, 1870, p. 18-2) Furthermore, that mathematics would be essentially analytic: "The critique of Kant's theory has shown that they cannot be synthetic a priori. The only remaining possibility is: that they must be analytic." (Stumpf, 1870, p. 18-2). What then is the foundation of the concept of number for Stumpf? Every number would consist of a "sum of units" ("Summe von Einheiten"), quite literally having the general form " $1+1+\ldots$ etc." More fundamentally, before getting to the concept of number, we start with the idea of plurality. When we have more than one single element, we can build a set of elements considered abstractly as mere "somethings", through a process of "Zusammenfassen" or collecting. Instead of "one plus one" we would have "something and something" ("Etwas und Etwas"). Such a collection would form a "Menge" or set. For Stumpf mathematics would be a fundamental and foundational science, it presupposes no truth derived from other sciences or from experience, while other sciences do require and presuppose the truths of mathematics, whenever and wherever they apply the tools of mathematics. Any quantification, measurement, 
statistic, etc. would therefore ultimately presuppose the analytic a priori axioms of mathematics. ${ }^{1}$

A very similar position was developed in more detail by Brentano and Stumpf's student Edmund Husserl, chiefly in his early works, specifically his 1887 Habilitation thesis "Über den Begriff der Zahl" ("On the Concept of Number") and his 1891 book Philosophie der Arithmetik ("Philosophy of Arithmetic"). Of course this merely shows a relationship between Husserl and Stumpf. A shared interest between master and pupil is not yet sufficient to make a claim about the presence of a shared interest or theory in the philosophy of mathematics in the School of Brentano at large. However, it is just as easy to find sources that attest without a shadow of a doubt that the foundations of mathematics were a shared concern of which they were all aware. Not just based on direct citations and references in their works, but also based on reviews of their works as belonging to a unified School. Alois Höfler, a student of Meinong, wrote a collective review (Höfler, 1894) ${ }^{2}$ of Husserl's Philosophy of Arithmetic, Benno Kerry's series of articles "Über Anschauung und ihre psychische Verarbeitung" (Kerry, 1885-1891) and Ehrenfels' article "Zur Philosophie der Mathematik" (Ehrenfels 1891). ${ }^{3}$ On its own, this would certainly already suffice to show that there was not just a vertical lineage, but cross-connections among the Brentanists writing on the philosophy of mathematics (Ierna, 2017a). The more important claims, however, are the second and third, which regard the content of such a shared "Brentanist Philosophy of Mathematics" (Ierna, 2011). What would its basic tenets be? At the core: that mathematics is analytical, deductive, and a priori; meaning that its axioms would be based exclusively on the principle of non-contradiction.

Let us now look at Brentano himself as originator of the School and its philosophy of mathematics. Unfortunately we do not have a published work by Brentano that explains his theory front to back, yet we do have an impressive number of manuscripts dealing with mathematics and logic, particularly lecture notes. This material from lecture notes is quite probably also indicative of the kinds of theories his students had access to and which their works are based on. Therefore we see that Brentano indeed separates knowledge based on experience from knowledge based on a priori principles, exactly like Hume: "Hence we obtain the result that matches that of Hume. The axioms of mathematics do one and all bear the characteristic of the principle of noncontradiction." (Brentano, Q 8, p. 201) Indeed, in his lectures Brentano provides

1 This paragraph is partially based on Ierna, 2015 .

2 For an annotated translation of Höfler's review, see Ierna, 2013.

3 Brentano had also annotated a copy of Ehrenfels' 1891 article with some critical remarks. 
extensive proofs against Kant's conception of mathematics and geometry as the prime example of sciences that are synthetic a priori. Brentano spends numerous pages in order to show that they really are analytic a priori and can be derived from the principle of non-contradiction alone. Should one wonder why Brentano, the author of the Psychology from an Empirical Standpoint would care so much about mathematics, specifically the analytic, a priori, and deductive nature of mathematics, we only need to look at the foundational role he assigns to it:

Mathematics reveals in a clear and understandable way the fundamental nature of all true scientific investigation. There is no better field of study for gaining one's first clear view of laws, deduction, hypothesis, and many other important logical concepts.

BRENTANO, 1874, p. 34; 1995, p. 21

Of course, the Psychologie is not itself a work that focuses on the philosophy of mathematics, and it only has quite general pronouncements about the position of mathematics in the system of the sciences. What we really need is a treatise that establishes Brentano's position on the topic in the same way that his Vom Ursprung Sittlicher Erkenntnis (translated as "The Origin of Our Knowledge of Right and Wrong") established his views on ethics. Happily, we do have precisely such a treatise, titled Über den Ursprung der mathematischen Erkenntnis ("The Origin of Our Knowledge of Mathematics") contained in the massive convolute on Megethology (specifically Meg 3a/40015-40038). In it, we find direct and explicit support for our second claim:

Mathematics is not an inductive, but a purely deductive, and in this sense, a priori science. Indeed, were it not, then there would be no science at all, neither deductive nor inductive. Because it is not induction that sanctions deduction, but deduction, and specifically mathematical deduction, that sanctions all rational scientific justified induction.

Meg 3a, 40025f.

\section{Brentano's Logicism}

We are now slowly moving into position to begin to establish the plausibility of our third claim: that the Brentanist philosophy of mathematics is a form of logicism. What do I mean when I say "logicism"? I certainly do not mean a position that is in all respects identical to that of Gottlob Frege. In a more general 
sense, "logicism" is the name for any position in the philosophy of mathematics that allows a progressive reduction of higher mathematics to elementary arithmetic and of arithmetic to logic. ${ }^{4}$ This implies that logic is more fundamental, i.e. more general, than mathematics. ${ }^{5}$ How would this reduction be effected?

The reduction of arithmetic to logic can be achieved through a definition of number based on set theory. We find support for such a reduction in several of Brentano's manuscripts, among which I will mainly concentrate on two here, namely "Von der Zahl und dem analytischen Charakter der algebraischen Wahrheiten" (Meg 2, "On Number and the Analytical Character of Algebraic Truths") and "Der Begriff Zahl" (Meg 37, "The Concept of Number").

First of all, recall the approach to Inbegriffe based on collection ("Zusammenfassung") familiar from Stumpf and Husserl; Brentano provides an account of sets along the same lines: ${ }^{6}$

There are indefinite concepts. Under them can fall things that are really different from one another, we often collect these together [zusammengefasst] and call the whole that we have constructed as a multiplicity of objects of the concept [Vielheit von Gegenständen des Begriffes].

Meg 2, 40009

Hence, through the process of collection we obtain as a result a set of objects which forms the extension of a concept. Having grouped the objects together in a set, we can then consider them simply as numerically distinct instances falling under such a concept:

Hence we call an A, and a B which is really different from it, that conform to the concept M, collectively as a multiplicity of M. Conversely, we indicate each $\mathrm{M}$ as a unit of $\mathrm{M}$ [Einheit von $\mathrm{M}]$.

Meg 2, 40009

Brentano here describes the relation of a set and its elements in almost mereological terms: the set is a whole, the elements its parts. Specifically, with respect

4 Consider the various definitions quoted by Hintikka, 2009, p. 271: "Logicism can be characterized as the doctrine according to which mathematics is, or can be understood as being, a branch of logic."

5 In the whole School of Brentano, Husserl was probably the most explicit about this, stating in his famous letter to Stumpf of February 1890 that the arithmetica universalis is nothing but a piece of logic ("ein Stück formaler Logik"), see Husserl, 1983, p. 248 and Husserl, 1994, p. 161.

6 Brentano's discussion of sets and Inbegriffe was without any doubt influenced by Bolzano's Paradoxien des Unendlichen. We can find extensive excerpts with comments in the Megeth- 
to the concept under which they are collected the set is a multiplicity and the element its units, exactly parallel to the structure of a number as "Vielheit von Einheiten". First we have to consider each element in the set as despoiled of all other defining characteristics and only consider it as "member of M". From that point of view: "jede Einheit von M erscheint der anderen gleich" ("Every unit of M seems the same as every other"). Yet we can distinguish and count them:

If in the multiplicity of collected M's there is just one different from one other, then the multiplicity is a magnitude [Größe], which surpasses the unity by one unit [die Einheit um eine Einheit übersteigt]. Such a multiplicity we call two.

Meg 2, 40009

This structure, based on mere numerical difference of the elements in a set, allows us to count the elements and establish the cardinality of a set, i.e. its magnitude. Then we can also order sets according to their magnitude. Numbers are then defined as multiplicities of units which express the quantity of a set: "Zweiheit von M" "Dreiheit von M" etc. ("twoness of M", "threeness of M"). Every set is then categorized as a specific n-tuple expressing its magnitude or numerosity. ${ }^{8}$ The numerosity of a set is determined by structural relations of identity and difference among the component elements.

Of course, in order to establish the magnitude of the set, we have to go though all the different elements and count them. Yet, even though the process of counting requires temporal succession, Brentano claims that: "Die mathematischen Wahrheiten sind [...] an sich in ihrer Gültigkeit von der Zeitanschauung ganz independent." "The validity of mathematical truths considered in themselves is wholly independent of the intuition of time." Meg 2, 40012 $)^{9}$

ologie. Brentano was also quite up to date on his contemporary set theory. Indeed, Brentano had read and annotated Cantor's articles and critically discussed his theories of infinity and the continuum in his lectures. For an in-depth analysis of Brentano's theory of the continuum in comparison to i.a. Dedekind and Cantor, see Massin, 2018.

7 Compare to the discussion in Husserl, 1887, p. 42: "When a concrete Inbegriff of two contents is given to us and we assign it the number two, then this means: we direct out attention merely to the fact that there is one content and one other content; this is not based on the specificity [of the respect in which the contents differ], but merely on the fact of the difference."

8 Compare Ehrenfels, 1885, p. 13: "If we disregard all particularities in the presentation of the foundations of a relation of difference, and only take heed of the fact that they are the foundations of such a relation, then we have the concept of twoness." Also see Ierna, 2017b, pp. $17 \mathrm{of}$.

9 Exactly like Husserl will do in 1887 (p. 28, with a predictable dig at Kant), and Thesis IV: "Der Zeitbegriff ist in dem Zahlbegriff nicht enthalten." "The concept of time is not included in the concept of number"). 
As an intermediate result, we can already see how the philosophy of mathematics contained in Brentano's unpublished manuscripts matches central tenets we already knew from the works of his students. The account of collecting, distinguishing, counting, etc. is very close to Husserl's discussion in his habilitation essay and first book. ${ }^{10}$ Yet, Husserl's discussion is generally considered as a more detailed development of Brentano's theories as we know them from his lectures on logic, which Husserl attended. However, as we discover more and more of the materials in Brentano's Megethologie we see that Brentano had already developed his philosophy of mathematics in considerable detail. Let us then look at what he has to offer.

One of the central criticisms Brentano levelled against Kant had to do with his conception of mathematical judgments as synthetic a priori (Q 8, 173: "Die Darstellung, die Kant von dem ganzen Vorgange gibt, ist falsch.", "The characterization that Kant gives of the whole process, is wrong."). Brentano vehemently objected to this new type of judgment and argued that mathematics consisted entirely of analytic a priori judgments. Hence, he stated quite unambiguously:

When I say e.g. " 7 is $4+3$ " then one expression is an analytical definition of the other. The analysis would be even more complete if we would sum up the units one by one.

Meg 37, 40529

In other words, the numerals " 7 ", “ 4 ", and “ 3 " are just convenient names that express certain set-theoretical structures, i.e. sums of elements. Accordingly, " 3 " is the name used to express the numerosity of sets (multiplicities of units) which have the structure of triplets. The numeral " 3 " actually means " $1+1+1$ ". Such a sum of units is cumbersome and impractical, and hard to keep track of, which is why we use the symbolic concepts of number (using signs such as " 3 ") instead the proper ones in mathematics, as Husserl extensively argued. So the analysis of " 7 ", " 4 ", and " 3 " (as well as " $7+5=12$ ") yields simply a complete tautology, listing identical sums of ones on either side of the equation, with merely the brackets to distinguish them: $1+1+1+1+1+1+1=(1+1+1+1)+(1+1+1)$. The reduction of any higher number form to mere sums of ones is what Brentano

10 For a more detailed and extensive discussion of Husserl's early philosophy of mathematics and logic in the context of the School of Brentano, see Ierna, 2005 and Ierna, 2006, as well as Chrudzimski, 2009. Due to the recent publication of Ehrenfels' dissertation, the significant similarities to Husserl's early position that can be found in it, strengthen the idea of a common source in Brentano. See the comparisons and parallels in Ierna, $2017 \mathrm{~b}$. 
means with "complete analysis" (Q 8, 176: "Dann ist das Ganze nur ein analytisches Urteil.", "Then the whole is just an analytical judgment.").11

Of course, the status of some numbers is contentious, if we define number as "multiplicity of units". Indeed, this was the common definition in the School of Brentano (as well as being a very classical one), which necessitated a separate introduction of one and zero as numbers. Given that one and zero are in many theories considered as the most fundamental building blocks of mathematics, it is quite significant how we can give an account of them. Brentano also explicitly points out this issue:

We do not just call number what corresponds to an addition of units, but also one single unit [Einheit] by itself and even what we express by zero, which we could call the nullity [die Keinheit].

Meg 37, 40529

These numbers need to be introduced into the system of numerals and numbers, which can only be done if we can explain the foundation of the concept of number itself.

Now how do we get to o? How to one? How to 2 ? etc. Who explains this, has explained the origin of the concepts of number and thereby the concept of number itself.

Meg 37, 4053ㅇ

The concept of number is the core issue of the treatise and the foundation of the concept of number involves an operation that is essentially logical, given the specific reform of logic that Brentano proposed (see Simons, 2004). His reform of Aristotelian syllogistic wanted to base all forms of judgment, universal and particular, affirmative and negative, on existential judgments. This would reflect the intuition that truth and existence would stand in a correspondence relation: to say of what is, that it is, is the truth. It also had the advantage of avoiding universals, because Brentano reformulated the universal affirmative as a negative existential judgment: instead of "all triangles have two right angles as sum of their internal angles" or "the triangle has etc.", Brentano

11 The argument is very close to Bolzano, 2004, § 8, p. 135: "On the Kantian Theory of the Construction of Concepts through Intuitions". It is likely Brentano was (directly or indirectly) aware of Bolzano's analysis. For more details on Bolzano's criticism of Kant in this respect, see Leclercq, 2017. 
proposed to reformulate this as "there is no triangle that does not have etc." The foundation of logic would be the theory of judgments (Urteilslehre) based on accepting or rejecting the existence of a certain object. Hence, we should read the following statement in this light:

We obtain o by rejection [Leugnung] of what is presented in the general concept. The opposite is its acceptance [Anerkennung].

Meg 37, 40530

This would place the logical operations of acceptance and denial, i.e. affirmative and negative judgments, at the foundation of the set theory underlying the concept of number and thereby basic arithmetic. Once we have zero by negation and one by affirmation of the existence of the element of a set, i.e. the empty set and a singleton, we can then generate the numbers as outlined above. Numerals $(2,3,4$, etc.) are a convenient shorthand for sums of ones $(1+1$, $1+1+1,1+1+1+1$, etc.), each of which can now be understood as following from the logical operation of an affirmative existential judgment.

This account, involving acts of judging, might invite accusations of psychologism, however Brentano quite explicitly states that while we do obtain numbers by counting the objects of a set, such numbers express the structure of a set quite independently of time and space. While the construction of the set might depend of mental acts, logical acts of accepting and denying, ultimately numbers express an abstract structure. There is a one-to-one correspondence between the elements in a set (i.e. objects falling under a concept, having a specific property) and the multiplicity of ones (i.e. these objects considered merely as units). In other words, the elements and the ones are isomorphic: each is to be understood as merely self-identical and (numerically) different from all others.

The concretum [the object] of which we predicate [the general concept], is one. However, given that the concept is universal, we can find different concreta that correspond to it. I acknowledge [erkenne] of each that it corresponds to it and yet that one [concretum] is not the other.

$\operatorname{Meg} 37,40530$

Multiple instances can fall under the same concept. Each instance as such is equal to each other as instance of the same concept, yet of course all are different, separate instances. Instead of flowing together indistinctly, these instances are countable. 
If I collect these as object of a presentation, then I call the whole given in this way, with respect to the parts that belong to it, corresponding to a general concept, a set $[$ Menge], and specifically 2 , if the set is 1 and 1 [etc.].

Meg 37, 40530

Hence, the foundation of the concept of number is positive existential judgment, i.e. the logical operation of affirming that the object exists as member of a set. These members or elements are countable and the resulting sets and numbers can be ordered according to their magnitude.

\section{$3 \quad$ Concluding Remarks}

Does all this make Brentano a logicist? If we interpret logicism very narrowly as a highly specific current in the foundations of mathematics starting with Frege, then the answer obviously is no. However, if we are allowed to take a slightly broader view of logicism, ${ }^{12}$ then perhaps the evidence adduced here might suggest the answer is yes. I do not want to state my claim too radically or strongly here, in absence of a critical edition of Brentano's manuscripts. There are around 800 unpublished pages of notes, letters, and treatises all on mathematical topics: the continuum, infinity, the foundations of mathematics and logic, numbers, the calculus of probability, inductive vs deductive, etc. Nevertheless, if we take Brentano's reform of elementary logic seriously, and acknowledge that acceptance and denial are then in essence logical operations, then I think I can make my case that Brentano's position is a form of logicism.

Moreover, having to pick from logicism, formalism, or intuitionism, then he is certainly more of a logicist than any of the others, though we might find elements of all three in the Brentanist philosophy of mathematics. In conclusion, however, I would rather argue that before any final pigeonholing can take place, more work is needed to bring out the original and unique elements in the approach to mathematics in the School of Brentano.

12 Consider the discussion of Dedekind's and Hilbert's logicism in Ferreirós, 2009. 


\section{References}

Bolzano, B. (1889). Paradoxien des Unendlichen. Berlin: Mayer \& Müller.

Bolzano, B. (2004). On the Kantian theory of the construction of concepts through intuitions. Appendix to Contribution to a better-grounded presentation of mathematics. In S. Russ (Ed.), The mathematical works of Bernard Bolzano (pp. 132-137). Oxford: Oxford University Press.

Brentano, F. (1874). Psychologie vom empirischen Standpunkte. Leipzig: Duncker \& Humblot.

Brentano, F. (1884/85). Die elementare Logik und die in ihr nötigen Reformen I. Vienna. Unpublished lecture notes, kept at the Husserl-Archives Leuven with signature Y 2.

Brentano, F. (1882/83). Metaphysik. Vienna. Unpublished lecture notes, kept at the Husserl-Archives Leuven with signature Q 8.

Brentano, F. (c. 190o). Über den Ursprung der mathematischen Erkenntnis. Unpublished manuscript, kept in Houghton Library, Harvard with the signature Meg 3 a.

Brentano, F. (c. 1900). Von der Zahl und dem analytischen Charakter der algebraischen Wahrheiten. Unpublished manuscript, kept in Houghton Library, Harvard with the signature Meg 2.

Brentano, F. (c. 19o6). Der Begriff Zahl. Unpublished manuscript, kept in Houghton Library, Harvard with the signature Meg 37.

Chrudzimski, A. (2009). Catégories formelles, nombres et conceptualisme. La première philosophie de l' arithmétique de Husserl. Philosophiques, 36(2), 427-445.

Ehrenfels, C. von (1885). Größenrelationen und Zahlen. Eine psychologische Studie, ed. by C. Ierna. Meinong Studien, 8, 185-234.

Ehrenfels, C. von (1891). Zur Philosophie der Mathematik. Vierteljahrsschrift für wissenschaftliche Philosophie, 15, 285-347.

Ferreirós, J. (2009). Hilbert, logicism, and mathematical existence. Synthese, 170(1), 3370.

Hintikka, J. (2009). Logicism. In A.D. Irvine (Ed.), Philosophy of mathematics (pp. 27129o). Amsterdam: Elsevier/North Holland.

Höfler, A. (1894). Besprechung von Kerry, "Über Anschauung und ihre psychische Verarbeitung", Husserl, Philosophie der Arithmetik, von Ehrenfels, "Zur Philosophie der Mathematik". Zeitschrift für Psychologie und Physiologie der Sinnesorgane, 6, 4458.

Husserl, E. (1887). Über den Begriff der Zahl: Psychologische Analysen. Halle: Heynemann'sche Buchdruckerei (F. Beyer).

Husserl, E. (1891). Philosophie der Arithmetik. Psychologische und logische Untersuchungen. Halle: C.E.M. Pfeffer (Robert Stricker).

Husserl, E. (1970). Philosophie der Arithmetik. Mit ergänzenden Texten (1890-1901), ed by L. Eley (Husserliana XII). Den Haag: Nijhoff. 
Husserl, E. (1983). Studien zur Arithmetik und Geometrie, ed by I. Strohmeyer (Husserliana XXI). Den Haag: Nijhoff.

Husserl, E. (1994). Briefwechsel. Vol. I Die Brentanoschule, ed by K. Schuhmann \& E. Schuhmann. Dordrecht: Kluwer.

Ierna, C. (2005). The beginnings of Husserl's philosophy (Part 1: From Über den Begriff der Zahl to Philosophie der Arithmetik). The New Yearbook for Phenomenology and Phenomenological Philosophy, 5, 1-56

Ierna, C. (2006). The beginnings of Husserl's philosophy (Part 2: Philosophical and mathematical background). The New Yearbook for Phenomenology and Phenomenological Philosophy, 6, 23-71.

Ierna, C. (2011). Brentano and mathematics. Revue Roumaine de Philosophie, 55(1), 149167.

Ierna, C. (2013). Husserl's Philosophy of Arithmetic in reviews. The New Yearbook for Phenomenology and Phenomenological Philosophy, 12(1), 198-242.

Ierna, C. (2015). Carl Stumpf's philosophy of mathematics. In D. Fisette \& R. Martinelli (Eds.), Philosophy from an Empirical Standpoint: Essays on Carl Stumpf (pp. 151-172). Amsterdam: Rodopi.

Ierna, C. (2017a). The Brentanist philosophy of mathematics in Edmund Husserl's early works. In S. Centrone (Ed.), Essays on Husserl's logic and philosophy of mathematics (pp. 147-168) Berlin: Springer.

Ierna, C. (2017b). On Ehrenfels' dissertation. Meinong Studien, 8, 163-184.

Kerry, B. (1885-1891). Über Anschauung und ihre psychische Verarbeitung. Vierteljahrsschrift für wissenschaftliche Philosophie, 9 (1885), 433-493; 10 (1886), 419-467; 11 (1887), 53-116, 249-307; 13 (1889), 71-124, 392-419; 14 (189o), 317-353; 15 (1891), 127167.

Leclercq, B. (2017). Are there synthetic a priori propositions? The paradigmatic case of mathematics, from Kant to Frege and Peirce. In V. Petrov, F. Beets \& K. Anderson (Eds.), Mathematics in philosophy (pp. 31-56). Louvain-la-Neuve: Chromatika.

Massin, O. (2018). Brentanian continua. Brentano Studien, 16, 229-275.

Simons, P. (2004). Judging correctly: Brentano and the reform of elementary logic. In D. Jacquette (Ed.), The Cambridge Companion to Brentano (pp. 45-65). Cambridge: Cambridge University Press.

Stumpf, C. (1870). Über die Grundsätze der Mathematik, ed by W. Ewen. Würzburg: Königshausen \& Neumann, 2008. 